\title{
BUDISTAS NO MEDITERRÂNEO
}

\begin{abstract}
ANDRÉ BUENO
Resumo: Neste ensaio, iremos fazer uma breve relação de algumas evidências que nos permitem compreender a passagem de elementos budistas no Mediterrâneo romano. Como cenário de disputas religiosas, o mundo romano recebeu as mais diversas religiões vindas do Oriente; e a presença budista foi devidamente identificada e reconhecida por autores da época, como iremos demonstrar.
\end{abstract}

Palavras-chave: Budismo, Império Romano, Religiosidades.

Nesse breve ensaio, buscaremos rastrear algumas evidências sobre o trânsito de missionários budistas no Mediterrâneo Romano, no período compreendido entre os séculos I ao III EC. As passagens textuais são fragmentárias, bem como os vestígios arqueológicos. Todavia, os budistas alcançaram certo reconhecimento pelos autores clássicos, de tal

\footnotetext{
${ }^{1}$ Pós-Doutor em História. Professor Adjunto de Antiguidade Oriental no curso de História da UERJ. E-mail para contato: antigauerj@gmail.com
}

modo que conseguiram se diferenciar dos outros indianos, sendo denominados em grego e latim como 'Samaneus'. A história do trânsito budista no Mediterrâneo insere-se no conjunto das relações desenvolvidas entre o império romano e o subcontinente indiano, no contexto das rotas euro-asiáticas surgidas após o estabelecimento da Rota da Seda.

Algumas indicações bibliográficas mais recentes podem confirmar o sentido de nossa proposta: Cimino (1996), por exemplo, conseguiu relacionar diversos vestígios materiais resultantes da relação entre Roma e os indianos. Tchernia (1995), Young (2001), Ball (2000), Bueno (2002), Tomber (2008) e MacLaughlin (2012) descrevem amplamente as relações entre o Ocidente Mediterrânico e o Extremo Oriente, demonstrando a amplitude desses contatos nos mais diversos âmbitos, fossem econômico, político ou cultural. Recentemente, Romanis e Maiuro (2015) organizaram uma coleção de ensaios dedicada exclusivamente às rotas indo-romanas. No âmbito das apropriações culturais, pude analisar a formação da iconografia indiana budista (BUENO, 2014) e das representações numismáticas dos 
soberanos Kushans (BUENO, 2015) a partir de modelos romanos, permeados pelo diálogo intercultural que se construiu em torno dessas rotas.

Assim, o presente texto busca apresentar mais um aspecto dessa multifacetada relação entre romanos e indianos: a presença budista no mundo mediterrâneo. Como dissemos, ela é pontual, mas significativa, tendo em vista que ela pôde ser identificada e descrita na literatura clássica. Ela se inseria no quadro das disputas políticas e religiosas que haviam se estabelecido no império, como bem analisou Greg Woolf (2009), em ensaio ao qual usualmente nos referimos. Pensamos, pois, que um relato desse gênero, embora descritivo e simplificado, pode auxiliar numa compreensão redimensionada da realidade cultural do mundo romano - e por extensão, do mundo antigo, de Ásia à Europa e África.

\section{ANTECEDENTES HistóRICOS}

Antes de começarmos um exame mais direto sobre as fontes do período romano, entendemos que a formulação de um quadro histórico anterior pode nos possibilitar informações relevantes. Poderemos observar, aliás, que as relações entre ocidentais e budistas eram mais antigas do que supomos.

O Budismo foi capaz de despertar o interesse dos gregos que habitavam na Índia, após a passagem de Alexandre Magno. Segundo Plutarco, o próprio Alexandre teria encontrado com sábios indianos, chamados Gimnosofistas (Vidas 9.64). Um deles, chamado Calano, acompanhou Alexandre (Ibid. 9.65), e ao ficar doente, decidiu imolar-se na frente do soberano (Ibid, 10:69) - uma passagem intertextual importante, como veremos adiante. 0 objetivo do sábio indiano era provar a sua crença absoluta na continuidade da vida após a morte. Não podemos afirmar o quanto esse fragmento é verídico, embora ele tenha sido citado por Arriano (Alexandre 63, cujo texto foi a provável fonte de Plutarco). Sabemos, de fato, que os budistas conseguiram causar uma forte impressão nos gregos.

As ações de promoção do Budismo levadas por Ashoka (304-232 AEC), soberano da dinastia
Maurya, surtiram um efeito gradual e constante nas vizinhanças indianas. Alguns se seus éditos, gravados em pedra, traziam textos escritos em grego (DHAMMIKA, 1993). Esse convívio com a doutrina budista converteu alguns deles. Um, inclusive, ficou famoso como monge budista, mas sabemos apenas seu nome indiano: foi Mahadhammarakkhita, citado no Mahavamsa (cap. 29) como um mestre yavana (grego) que peregrinou até o Ceilão para levar a fé búdica.

Menandro, soberano de um reino Greco-indiano situado na Báctria (hoje, área que compreende parte do Afeganistão) é também citado na documentação budista, como tendo sido convertido pelo monge Nagasena após um diálogo memorável, que ficou salvo no livro Milinda Panha (Milinda é o nome indiano de Menandro). Ademais, temos a longa convivência artística entre gregos e budistas, que fez nascer a escola de Gandhara (ver ZWALF, 1996 e BEGUIN, 2009). As mudanças no cenário político, com a vinda dos Kushans, implementaram esse panorama de trocas culturais, como podemos ver pela incorporação de vários motivos estéticos importados do mundo Greco-romano (BUENO, 2014 e 2015).

Os budistas estavam sendo atraídos em direção ao Mediterrâneo romano. Missionários proselitistas, que acreditavam numa doutrina universalista de libertação espiritual, eles dispunham de meios para dialogar com as culturas do Médio Oriente da época. É bem provável que alguns monges budistas soubessem o grego e o aramaico, e tivessem conhecimento de informações advindas das rotas que ligavam o Império Romano a China. Sabemos, por exemplo, que o reino da Pártia abrigou um importante templo budista na cidade de Merv, de onde sairia Anshigao 安世高(148-180 EC), príncipe parto convertido ao Budismo que migraria para a China, e transformaria num dos mais importantes tradutores de escrituras sagradas da antiguidade (ZURCHER, 1959, p. 32-34). Merv era uma das paradas principais dos caminhos que levavam ao Ocidente romano, e a comunidade budista ali instalada representaria uma base segura em direção ao Mediterrâneo. 
No contexto das disputas religiosas que envolviam o Império Romano, a presença budista tornou-se significativamente marcante, a tal ponto que eles são identificados na documentação romana de maneira específica. Analisemos, pois, algumas dessas passagens.

\section{FRAGMENTOS TEXTUAIS}

A primeira e mais marcante evidência da presença budista entre os romanos se dá em um curioso episódio ocorrido na Grécia. Augusto estava de passagem por Atenas, quando um sábio indiano decidiu imolar-se na frente do imperador. Provavelmente, o indiano queria impressionar Augusto, e trazê-lo para a fé budista. O fragmento é confirmado por três fontes diferentes: a Vida de Augusto, por Nicolau de Damasco; História de Roma, 9 por Dion Cássio; e Geografia de Estrabão, 15.1.73. Mas como sabemos que se tratava de um budista, e não de um indiano hindu, ou de outra religião qualquer?

A melhor indicação que temos, para acreditar que se tratasse de um sábio budista, foi a inscrição deixada na tumba de seus restos mortais. Conforme o texto de Estrabão,

Ele (Nicolau de Damasco) diz que em Antioquia, perto de Daphne, ele teve a chance de conhecer os embaixadores indianos que tinham sido despachados para César Augusto; que a carta indicava claramente mais do que três embaixadores, mas que apenas três haviam sobrevivido (foi o que ele soube), e o restante, principalmente por causa das longas viagens, tinha morrido; que a carta foi escrita em grego em um pergaminho; e que claramente mostrou que Porus foi quem a escreveu, e, embora ele fosse o governante de mais de seiscentos reis, ele estava ansioso para ser um amigo de César, e estava pronto não só para permitir-lhe uma passagem pelo seu país, onde quer que ele desejasse passar, mas também a cooperar com ele em tudo o que o honrasse. Nicolau diz que este era o conteúdo da carta a César, e que os presentes levados a César foram apresentados por oito mulheres seminuas, vestidas apenas com tangas sumárias e cheirando a perfume; e que os presentes consistiu em um Hermes, um homem que nasceu sem braços, a quem eu mesmo vi, grandes víboras, uma ser- pente de dez côvados de comprimento, e uma tartaruga de três côvados de comprimento, e uma perdiz maior que um abutre; e eles foram acompanhados também, segundo ele, pelo homem que queimou-se em Atenas; e que, enquanto alguns cometem suicídio quando sofrem adversidades, buscando a liberação de seus males por suas próprias mãos, outros o fazem quando a sua sorte é feliz, como foi o caso daquele homem; Ele (Nicolau) acrescenta que, apesar deste homem ter vivido como desejava até aquele momento, ele pensou que necessário, então, partir desta vida, para evitar que algo desagradável pudesse lhe acontecer se mais tempo se demorasse nessa vida; e, portanto, ele saltou sobre a pira com uma risada, com seu corpo nu ungido, vestindo apenas uma tanga; e que as seguintes palavras foram inscrita em sua tumba: "Aqui jaz Zarmanochegas, um indiano de Barigaza, que se imortalizou em conformidade com os costumes ancestrais dos indianos" (Geografia, 15.1.73)

Precisamos analisar o nome desse mestre indiano:

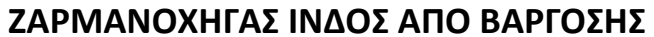

Zarmanochegas, um indiano de Barigaza.

Barigaza era uma cidade bem conhecida dos romanos, e é indicada no Périplo do Mar Eritreu (Caps. 41 e 47: ver FREZOULS, 1984), importante manual de navegação da época. No entanto, o nome 'Zarmanochegas' é sumamente estranho às línguas indianas. Eliot (1921) propôs, com grande plausibilidade, que se trataria de uma corruptela de 'Sramana Acharya', que significa Mestre (Acharya) Budista (Sramana). Halkias (2015) confirma essa versão, nos fornecendo mais detalhes sobre todo o evento.

Aparentemente, Plutarco esteve na Grécia, e confirmou a existência dessa inscrição (Vidas 10.69). Ele compara esse evento com o ocorrido com Alexandre, indicando que 'César' teria assistido evento semelhante. Como Plutarco compara as vidas de Alexandre e Júlio César, alguns tradutores supõem que fosse ele, e não Augusto, que estivesse no evento passado em Atenas. Porém, a indicação dos autores contemporâneos de Augusto aponta claramente que foi ele a testemunhar a imolação do sábio budista. Augusto, inclusive, recebeu embaixadas 
indianas, como é citado na Res Gestae (cap. 31) e em Floro (Epitomae 2.34). Assim, é possível pensar que os indianos estivessem cada vez mais presentes no mundo mediterrânico.

Curiosamente, o mesmo Estrabão (tendo como fonte a História Indika de Megastenes, hoje perdida) já sabia que existia uma diferença entre os Brâmanes (hindus) e aqueles que ele chama de Garmanes (budistas) (Geografia, 15. 1.60):

Quanto aos Garmanes, os mais honrados entre eles são chamados de Hylobii, que vivem nas florestas, vivendo de folhas e frutos silvestres, vestindo cascas de árvores, e abstendo-se de vinho e das delícias do amor. (...) Em segundo lugar, entre eles, estão os filósofos, que tem hábitos frugais, mas não saem dos mosteiros, e subsistem com grãos de arroz e cevada, que são dados a eles por quem Ihes implora favores ou hospitalidade. Dizem que são feiticeiros hábeis, capazes de conceder uma grande prole a quem desejar, escolhendo se meninos ou meninas; conseguem tratar doenças através da alimentação, sem remédios; e que seus medicamentos, pomadas e unguentos dos mais variados gêneros, são muito estimados, embora possam fazer mal. São resistentes e perseverantes em suas práticas, a ponto de conseguirem ficar dias parados, sem se mover, numa mesma postura. Existem também adivinhos e encantadores, que são hábeis nos ritos e costumes funerais, e que costumam pedir esmola nas aldeias e cidades. Outros ainda, mais refinados, dedicam-se a prática da santidade e da piedade, mas não abstém-se de discutir sobre assuntos relativos a morte; por fim, as mulheres, assim como os homens, estudam suas filosofias, e do mesmo modo, praticam abstinência sexual.

A descrição, tecnicamente correta, dá conta de identificar alguns dos principais elementos do Budismo: o ascetismo, os mosteiros, a meditação, os monges mendicantes e a presença de mulheres praticantes. Estrabão, pois, não teria concatenado as duas passagens. Isso não impediu, contudo, que o conhecimento sobre os budistas gradualmente se desenvolvesse. Na documentação posterior, como veremos, os Budistas são chamados de Samaneus (latinização mais aproximada de Sramana), um provável indicativo de que o conhecimento sobre o $\mathrm{Bu}$ dismo desenvolvera-se.

\section{O ARISTOCRATA ROMANO BUDISTA}

Proveniente desse mesmo período, um notável busto de bronze localizado no Museu Nacional de Roma nos permite ampliar nosso conjunto de referências. O busto é analisado em Ball (2000) e citado em MacLauglhin (2012), e se trata de um curioso vestígio da relação entre budistas e romanos.

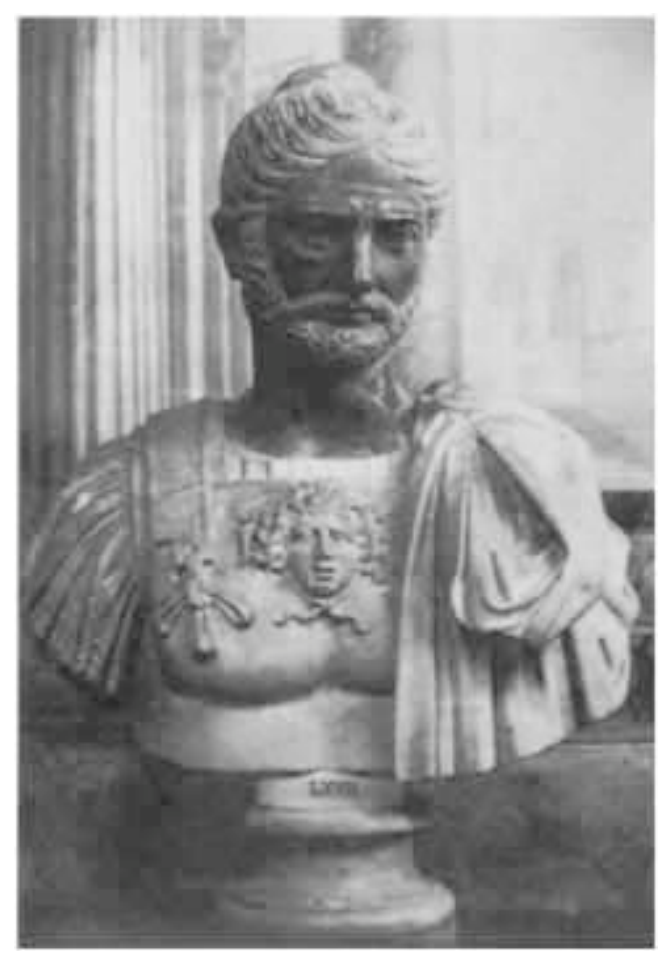

Figura 1. Busto de um oficial "Romano budista", supostamente, de Julius Bassianus, importante oficial romano do século 3. Fonte: BALL, 2000, p. 401.

Como podemos observar, trata-se de um oficial (um general?) que traja armadura romana e manto. A cabeça, porém, apresenta os elementos fundamentais da representação iconográfica budista de Gandhara, que funde técnicas Greco-romanas com símbolos búdicos. O cabelo, amarrado em coque no topo da cabeça, a ushnisha उष्णीष, representa uma elevação craniana que Buda alcançou em seu Nirvana, e é uma representação própria no cânone artístico budista. O rosto é barbado; isso indica que ele provavelmente não é romano, ou seria de um período mais tardio. É uma representação pouco usual, tendo em vista que a escola de Gandhara, inclusive, trabalhava materiais perecíveis ou pedra, sendo raras as expressões em bronze nesse período. 


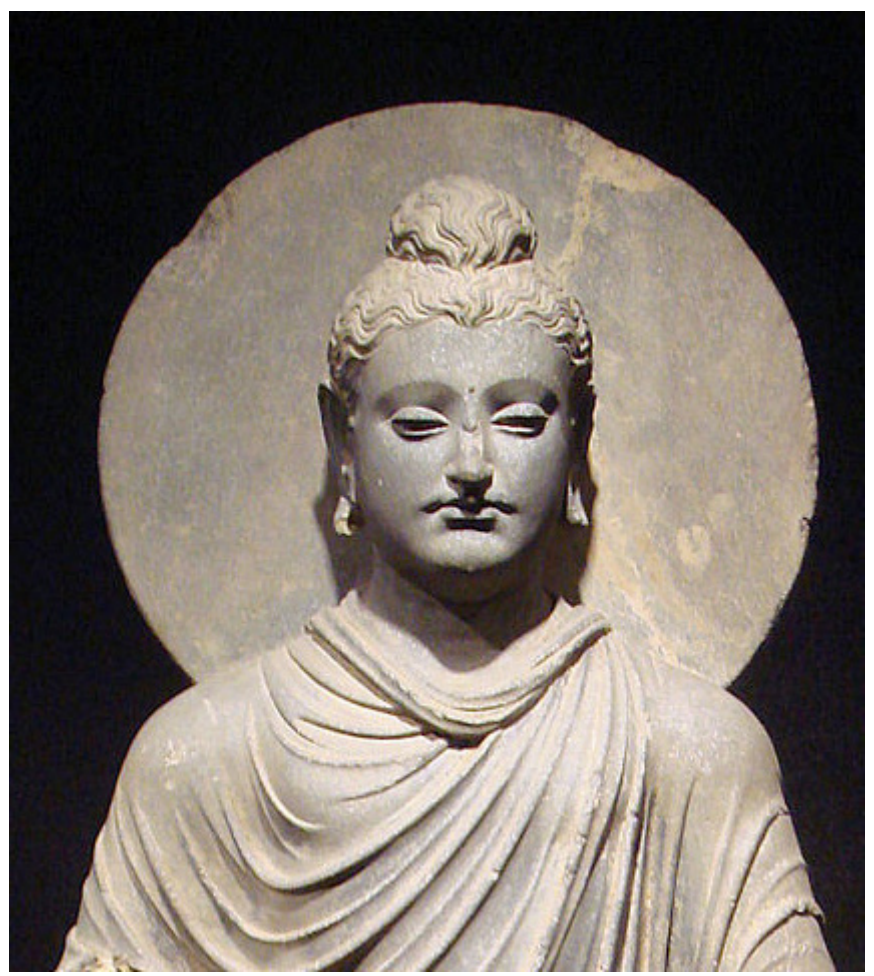

Figura 2. Detalhe de um Buda de Gandhara (séc. 1-2 EC). Note-se a Ushnisha no topo da cabeça. Fonte: https:// en.wikipedia.org/wiki/Gandhara\#/media/File:Gandhara Buddha (tnm).jpeg

As hipóteses que temos para explicar esse busto são variadas: trata-se, provavelmente, de um Buda ou de um devoto budista. Um Buda de armadura, porém, tratar-se-ia de uma figuração única, não encontrada na Índia. Isso nos leva a pensar, portanto, que se trata de um oficial. Mas qual seria a sua proveniência? Temos aqui três possibilidades: um romano convertido, ou um grego ou indiano (conversos ao Budismo) que serviam aos romanos. Novamente, porém, esbarramos no problema da autoridade: que grego ou indiano conseguiriam atingir um elevado posto militar no mundo romano desse período? E sendo um romano, como ele teria tido contato com budistas, a ponto de converter-se?

Ball (2000, p. 400-401) propõe que esse busto representaria o oficial Julius Bassianus (começo do séc. 3) importante aristocrata ligado a corte dos Severos, e magistrado na Síria no governo de Heliogábalo. Com o cuidado necessário, Ball defende que os romanos estavam vivendo um período de orientalização estética, o que não implicava numa conversão autêntica aos cultos asiáticos (embora essa não possa, também, ser descartada). A adoção do Budismo não seria estranha para Bassianus; a
Síria era um centro de debates religiosos, e o próprio Heliogábalo teria tido contato com indianos, como veremos adiante. Além disso, o mosteiro budista na Pártia já operava de forma regular, tendo em vista que nesse mesmo período Anshigao já havia se dirigido para a China.

A comparação dos bustos de Gandhara com o busto do oficial não deixa dúvida sobre a incorporação de padrões budistas em sua constituição; todavia, permanecem as questões sobre a origem e a biografia do personagem representado, deixando margem à especulação. $O$ importante, no caso, é reconhecer a existência dessa imagem, que manifesta a presença nítida de budistas - ou, ao menos, de seus cânones iconográficos - entre os habitantes do império romano.

Tarn (1966, p. 370) cita ainda uma peculiar gravação em pedra numa provável tumba budista no Egito, reproduzindo a informação de Sir F. Petrie no Journal of Royal Asiatic Society (1898, p. 875). A argumentação, baseada em um hieróglifo 'diferente' e 'desconhecido', é muito precária para sustentar que se tratasse de uma tumba budista; além disso, os budistas eram cremados, o que se trata de uma contradição. Contudo, o Egito romano, bem como as províncias do Oriente, também testemunharia a presença indiana através dos escritores cristãos, que debateriam de modo importante o discurso Budista.

\section{As EtNografiAs CRISTÃS}

$\mathrm{O}$ advento do Cristianismo proporcionou a expansão de um novo tipo de gênero literário: as Etnografias Religiosas. Alguns dos primeiros autores cristãos preocuparam-se em estudar e descrever as religiões que transitavam pelo Mediterrâneo, de modo a analisá-las e desconstruí-las.

No Egito, a Escola de Alexandria conheceu a importante obra de Clemente (150-215 EC), que descreveu com alguma precisão as diferenças entre os indianos hindus e os budistas: 
Os gimnosofistas indianos estão em grande número entre os filósofos bárbaros. Entre eles existem duas classes, os Sramanas e os Brâmanes. Os Sramanas que não moram em cidades, são chamados de Hylobii, não tem abrigo, vestem-se de cascas de árvore, alimentam-se de frutos maduros e bebem água com as mãos. (...) Não se casam, nem geram filhos. Alguns deles seguem os ensinamentos de Boutta

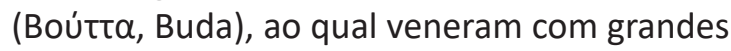
honras por sua santidade. (Stromata, 1.15)

Esse texto é significativo: ele mostra que os autores romanos podiam dispor de conhecimentos razoáveis sobre as diferenças religiosas entre os indianos. Embora o texto seja similar ao de Estrabão, Clemente insere os termos 'Sramana' e 'Bouta', mostrando um relativo aprofundamento nas informações. Isso pode ter uma razão mais direta: Clemente foi contemporâneo de Amônio Saccas (175-242 EC), e ambos foram mestres de Orígenes e Plotino. Essa conexão é fundamental, pois segundo Seeberg (1941), Amônio era indiano, e provavelmente budista, por conta de seu sobrenome (Saccas, uma provável corruptela do nome indiano Sakhya). Isso explicaria, em parte, a razão pela qual Plotino encantara-se com o pensamento indiano, bem como Orígenes acreditaria em uma forma de reencarnação, mesmo sendo cristão (HARRIS, 1982). Seus mestres - Clemente e Amônio - podiam discutir amplamente essas ideias na Alexandria da época, um centro multicultural e aberto aos estrangeiros.

Bardasano de Edessa (154-222 EC), escritor sírio e cristão, faz uma breve descrição dos hábitos religiosos dos indianos, e aparentemente tinha algum conhecimento sobre as variedades religiosas da Índia - embora fantasiasse bastante (BUENO, 2015b, p.32-49). Porfírio nos informa que Bardasano teria, inclusive, participado de um encontro entre sábios indianos e o imperador Heliogábalo. Mas Porfírio nos informa algo mais: ele confirma a diferença entre Brâmanes e Budistas, em um importante texto sobre a abstinência do consumo de carne (ibidem):

A organização política dos indianos é distribuída em várias partes, há uma tribo de homens sábios e divinos, que os gregos se acostumaram a chamar de Gimnosofistas. Entre eles, existem duas seitas, a dos Brâmanes e dos Samaneus. Os Brâmanes acreditam receber a sabedoria divina por meio de um tipo de sucessão, parecida com o sacerdócio. Já os Samaneus são eleitos, são aqueles que desejam possuir o conhecimento divino. As indicações a esse respeito foram narradas pelo Babilônio Bardasano, que viveu no tempo de nossos pais, e estava familiarizado com os indianos, que foram enviados em grupo, junto com Damadamis, para visitar César. Os Brâmanes têm uma origem comum, e são provenientes de um pai e uma mãe. Os Samaneus, como dissemos, não provém de uma família, mas de todo o país dos indianos (Abstinência de Alimentos Animais 4. 17)

Porfírio continua seu longo parágrafo explicando que os Samaneus praticam uma série de abstinências, vivem em templos ou mendigando, atendem aos reis para aconselhá-los e, diante das contrariedades da vida, optam pela auto-extinção. Em quase todos os pontos, sua narrativa reproduz e confirma as informações apresentadas pelos outros autores (Ibid 4. 17)

No campo da mitografia, São Jerônimo é que nos apresenta ainda um relato precioso: ele nos informa sobre a lenda de que Buda teria nascido de uma princesa virgem, tal como teria ocorrido com Jesus. Isso mostra um conhecimento razoável sobre as tradições budistas, muito dificilmente obtido por acaso: "Para os Gimnosofistas da Índia, a opinião da maioria sobre Buda, o fundador de sua religião, é que ele nasceu do lado de uma princesa virgem" (Contra Joviano, 1.42).

\section{O FIM DAS EXPERIÊNCIAS BUDISTAS NO MediterRÂNeO}

Esses esparsos fragmentos não nos permitem dimensionar o alcance da influência budista no Mediterrâneo. Pelas breves indicações que pudemos listar, sua atuação provavelmente limitou-se ao contexto Oriental - com exceção do singular busto do oficial romano. Elaine Pagels (1991) cita a provável influência dos indianos nos textos gnósticos, mas esta também é uma especulação; apesar das indicações sobre reencarnação, os textos não deixam margem a indicações mais completas. Quem 
colaborou para a difusão dessa ideia foi, justamente, o grande crítico da Gnose, Irineu de Lyon (130202 EC), em seu livro Contra as Heresias.

E de forma abrupta, desaparecem as menções aos budistas. Por qual razão isso teria acontecido? O que ocorreu com os budistas, na verdade, foi o mesmo que aconteceu com todas as outras religiões que disputavam espaço no império romano. Elas foram atropeladas pela expansão do Cristianismo, que gradualmente se expandiu por todas as partes do mundo Greco-romanizado. Embora atraente e bem elaborado, o discurso budista era complexo, e nem sempre de fácil apreensão. O Budismo implicava na absorção de novos conceitos, e de uma prática meditativa sutil com o qual os mediterrâneos não estavam familiarizados. O Cristianismo primitivo era muito mais simples, tinha uma perspectiva salvacionista e otimista para a vida após a morte, e limitava-se a um conjunto de regras e práticas facilmente compreensíveis para viver em sociedade. Além disso, o Cristianismo nascera no contexto do Império Romano, dialogando diretamente com os conflitos e anseios da época. O Budismo, provavelmente, era mais atraente para aqueles que possuíam alguma experiência com Filosofia - e que não eram a maioria.

Outro fator que desestimulou a ida dos Budistas para o Ocidente foi a virada em direção à China. No século 3, mesmo com as crises dinásticas, a sociedade chinesa continuava receptiva a vinda de novas doutrinas do exterior (ZURCHER, 1959). O Budismo encontraria um espaço de diálogo amplo - e de fato, não só os budistas, como outras religiões orientais, tentariam migrar para a China, como foi o caso também dos Judeus, dos Mazdeítas, Maniqueístas e Nestorianos.

Ao longo do século 4, pois, o Mundo Mediterrânico veria a ascensão do Cristianismo - permeada de novos conflitos - e o desaparecimento, entre outros, dos monges indianos vestidos de açafrão. Contudo, o resgate dessa passagem histórica nos revela, mais uma vez, o quão multifacetado era a vivência religiosa dentro do Império Romano, levando-nos a rever as concepções compartimentadas e restritivas sobre a História do Mundo Clássico.

\section{BUDDHISTS IN THE MEDITERRANEAN}

Abstract: In this essay, we will make a short list of some evidence to allow us to understand the passage of Buddhist elements in the Roman Mediterranean. As the scene of religious disputes, the Roman world received the most diverse religions coming from the East; and the Buddhist presence has been identified and recognized by the authors of the period, as we will demonstrate.

Keywords: Buddhism, Roman Empire, Religiosities.

\section{REFERÊNCIAS BIBLIOGRÁFICAS}

BALL, Warwick. Rome in the East: The Transformation of an Empire. London: Routledge, 2000.

BEGUIN, Gilles. Buddhist art: an historical and cultural journey. Bangkok: River Press, 2009.

BEHRENDT, Kurt. BRANCACCIO, Pia. Gandharan Buddhism. British Columbia: UBC, 2006.

BUENO, André. Augusto Índico: a apropriação da imagem de Augusto pelos soberanos Kushans, sécs. 1- 2 eC. In: CAMPOS, C. \& CANDIDO, M. (org). Caesar Augustus: entre práticas e representações. Vitória/Rio de Janeiro: NEA-UERJ, 2014, p. 300-316.

\section{China, Roma e o Sistema Mundial Nos Sé-} culos I ao III d.c. Dissertação de Mestrado. Niterói: UFF, 2002.

Etnografias religiosas no Livro das Leis dos Países, de Bardasano de Edessa. NEARCO - Revista Eletrônica de Antiguidade, Rio de Janeiro, Ano VIII, Número II, 2015. p. 32-49.

Um Buda para o Mediterrâneo: A Criação da Imagem do Buda em Pé a partir de um Modelo Romano. Rever, São Paulo, v.14, n.1, 2014 p.138-151.

CIMINO, Rosa. S. et al. Ancient Rome and India: commercial and cultural contacts between the Roman world and India. Nova Delhi: Munshiram Manoharial, 1996.

CLEMENTE DE ALEXANDRIA. Stromata. Trad. William Wilson. Buffalo: Christian Literature Publishing Co., 1885.

DHAMIKKA, Shravasti. The Edicts of King Asoka. Sri Lanka: Buddhist Publications Society, 1993.

ELIOT, Charles. Hinduism and Buddhism: An Historical Sketch. 3vs. London: Routledge, 1921.

ESTRABÃO. The Geography of Strabo. Harvard: Loeb Classical Library edition, 1917. 
FREZOULS, E. Quelque einsegnements du Periple de la mére Eryhtrée, Ktema N.9 Strasbourg: V.S.H., 1984.

GEIGER, Wilhelm. BODE, HAYNES, Mabel. (transl.). The Mahavamsa or, the great chronicle of Ceylon. London: Pali Text Society, 1912.

HALKIAS, Georgios. The Self-immolation of Kalanos and other Luminous Encounters Among Greeks and Indian Buddhists in the Hellenistic World. Journal of the Oxford Centre for Buddhist Studies, Oxford, v. 8, 2015 p. 163-186.

HARRIS, Ransom B. Neoplatonism and Indian Thought. Albany: Suny Press, 1982.

MCLAUGHLIN, Raoul. Roma e o Oriente Distante - Rotas Comerciais Para As Terras Antigas da Arábia, Índia e China. São Paulo: Rosari, 2012.

The Roman Empire and the Indian Ocean: Rome's Dealings with the Ancient Kingdoms of India, Africa and Arabia. London: Pen \& Sword, 2014.

PAGELS, Elaine. Os evangelhos gnósticos. São Paulo: Cultrix, 1991.

PLUTARCO. Vidas Paralelas. São Paulo: Paumape, 1992.

PORFÍRIO. Select works of Porphyry. Trad.Thomas TayIor. London: T. Rodd, 1823.

ROMANIS, Federico. MAIURO, Marco. (ed.). Across the Ocean: Nine Essays on Indo-Mediterranean Trade. Columbia Studies in the Classical Tradition, 41. Leiden; Boston: Brill, 2015.

SEEBERG, Erich. Ammonius Sakas. Zeitschrift für Kirchengeschichte, vol. LX, 1941, p. $136-170$.

TARN, William. The Greeks in Bactria and India. Cambridge: Cambridge University Press, 1966.

TCHERNIA, André. Moussons et Monnaies: les voies de commerce entre le monde gréco-romaine et l'Inde. Annales, Paris, no 5, 1995.

TOMBER, Roberta. Indo-Roman Trade: From Pots to Pepper. Bristol: Bristol Classical Papers, 2008.

XAVIER, Raul. Milinda Panha. Rio de Janeiro: Livros do Mundo Inteiro, 1973.

WOOLF, Greg. World Religion and World Empire in the Ancient Mediterranean. In: CANCIK, Hubert. e RUPKE, Jörg. (orgs.) Die Religion des Imperium Romanum. Tubingen: Mohr Siebeck, 2009.

YOUNG, Gary K. Rome's Eastern Trade: International Commerce and Imperial Policy 31 BC - AD 305. London: Routledge, 2001.
ZURCHER, Erik. The Buddhist Conquest of China: The Spread and Adaptation of Buddhism in Early Medieval China. Leiden: Brill, 1959.

ZWALF, Wladimir. Buddhism: art and faith. London: British Museum, 1996. 